\title{
Severe Permanent Encephalopathy in Acute Lymphoblastic Leukemia
}

\author{
Bernard L. Maria, Maureen Dennis and Marc Obonsawin
}

\begin{abstract}
As survival rates for childhood acute lymphoblastic leukemia have increased, concerns over improved quality-of-life have also increased. Although 3-10\% of children may experience acute transient neurotoxicity during induction chemotherapy, they are felt to be at low risk for late sequelae. We report three previously healthy boys with newly-diagnosed acute lymphoblastic leukemia who presented with obtundation and severe seizures during late induction with a standard four drug chemotherapy regimen. While all three are disease-free survivors, they unexpectedly have persistent and medically intractable partial complex seizures, broad-based neuropsychological impairment and striking neuroimaging abnormalities. These findings suggest that children with leukemia who develop an acute encephalopathy during induction chemotherapy are at risk for long-term neurological and neuropsychological sequelae, despite the cessation of further potentially neurotoxic therapy.
\end{abstract}

RÉSUMÉ: Encéphalopathie sévère permanente dans la leucémie lymphoblastique aiguë. Dupuis que le taux de survie des enfants atteints de leucémie lymphoblastique aiguë a augmmenté, on se préoccupe davantage d'améliorer leur qualité de vie. Bien que 3 à $10 \%$ des enfants peuvent manifester une neurotoxicité aiguë transitoire pendant la chimiothérapie inductrice de rémission, ils sont considérés comme présentant un risque faible de séquelles tardives. Nous rapportons les cas de trois garçons auparavant en santé, chez qui on a diagnostiqué une leucémie lymphoblastique aiguë et qui ont présenté de l'obnubilation et des crises convulsives sévères pendant l'induction tardive, sous un régime chimiothérapeutique constitué de quatre médicaments standards. Bien que les trois enfants survivent sans évidence de leur maladie, il est surprenant de constater qu'ils présentent des crises partielles complexes persistantes et résistantes au traitement, une atteinte neuropsychologique étendue et des anomalies évidentes à l'imagerie cérébrale. Ces constatations suggèrent que les enfants atteints de leucémie, qui développent une encéphalopathie aiiguë pendant la chimiothérapie inductrice de rémission, sont à risque de présenter des séquelles neurologiques et neuropsychologiques à long terme malgré l'arrêt de toute thérapie potentiellement neurotoxique.

Can. J. Neurol.Sci. 1993; 20: 199-205

Significant improvements in survival rates for childhood acute lymphoblastic leukemia has required therapy directed at occult central nervous system leukemia. ${ }^{1.2}$ Intrathecal therapy with methotrexate, cytosine arabinoside and hydrocortisone are used widely for control of meningeal leukemia and are part of intensification regimens designed to reduce treatment failures in high risk patients. ${ }^{3}$ At The Hospital For Sick Children, University of Toronto, children with acute lymphoblastic leukemia between the ages of $1-2$ years or $\geq 10$ years at diagnosis, with a white blood count $>50,000 / \mathrm{mm}^{3}, \mathrm{a} \mathrm{L}_{2}$ marrow morphology ( $>50 \% \mathrm{~L}_{2}$ blasts), a lymphoma syndrome or sanctuary disease in the central nervous system or testicle have been treated with a high-risk acute lymphoblastic leukemia protocol (Table 1).

Various multiorgan complications have been associated with the drug induction regimen. Moreover, acute changes in mental status, transient neurologic dysfunction, seizures, and various other acute and chronic disturbances have been observed from cancer-related and/or treatment-related effects. ${ }^{4.5}$ Acute changes in mental status during therapy for acute lymphoblastic leukemia have been reported in 3-10\% of children but chronic encephalopathy has been a rare occurrence when children have not received cranial irradiation and there is no systematic data available on neurotoxicity to determine which children may be at risk for clinically significant impairment of central nervous system function. ${ }^{6}$

In a ten year period (1980-1990), approximately 2,000 children with acute lymphoblastic leukemia were treated at The Hospital for Sick Children. We report three children identified with acute lymphoblastic leukemia in remission which were treated with the high risk protocol and sustained an acute change in mental status with seizures but who unexpectedly have had persistent medically intractable partial complex seizures, broadbased neuropsychological impairment and neuroimaging abnormalities 15 mos. to 7 years after the initial event. Severe residual neurological sequelae may sometimes result from induction therapy for acute lymphoblastic leukemia. While chemoprophylaxis alone may be associated with severe chronic encephalopathy, such complications have generally been previously attributed to cranial irradiation in combination with methotrexate.

From the Pediatric Neuro-Oncology Program (B.L.M.), Department of Pediatrics, University of Florida College of Medicine, Gainesville, Florida; the Department of Psychology (M.D., M.O.), The Hospital For Sick Children, University of Toronto

Received January 4, 1993. Accepted in final form March 16, 1993

Reprint requests to: Bernard L. Maria, M.D., University of Florida College of Medicine, Chief, Division of Pediatric Neurology, Box J-296, J.H.M. Health Center, Gainesville, Florida, USA 32610 
Table 1: High Risk Chemotherapy Protocol for Acute Eymphoblastic Leukemia

\section{Day of 'Therapy}

\begin{tabular}{|c|c|c|c|c|}
\hline 0 & \multirow[t]{3}{*}{ VCR } & \multirow[t]{3}{*}{ Dauno } & Lasp & \multirow[t]{6}{*}{ IT AraC } \\
\hline 3 & & & Lasp & \\
\hline 5 & & & Lasp & \\
\hline 7 & \multirow[t]{3}{*}{ VCR } & \multirow[t]{3}{*}{ Dauno } & Lasp & \\
\hline 10 & & & Lasp & \\
\hline 12 & & & Lasp & \\
\hline 14 & \multirow[t]{3}{*}{ VCR } & \multirow[t]{3}{*}{ Dauno } & Lasp & \multirow[t]{4}{*}{ IT MTX } \\
\hline 17 & & & Lasp & \\
\hline 19 & & & Lasp & \\
\hline 21 & VeR & \multicolumn{2}{|l|}{ Dauno } & \\
\hline 22 & \multicolumn{4}{|c|}{ ACUTE ENCEPHALOPATHY CASE \# 1} \\
\hline 28 & \multirow{2}{*}{\multicolumn{4}{|c|}{ ACUTE ENCEPHALOPATHY CASE \# $2^{\text {IT MTX }}$}} \\
\hline 30 & & & & \\
\hline 33 & \multicolumn{4}{|c|}{ ACUTE ENCEPHALOPATHY CASE \# 3} \\
\hline
\end{tabular}

Note: Vincristine (VCR), $1.5 \mathrm{mg} / \mathrm{m}^{2}(\max 2.0 \mathrm{mg}) \mathrm{IV}$; Daunomycin (Dauno), $25 \mathrm{mg} / \mathrm{m}^{2} \mathrm{IV}$; L-asparaginase (Lasp), 6000 units $/ \mathrm{m}^{2} \mathrm{IM}$; Prednisone $60 \mathrm{mg} / \mathrm{m}^{2}$ ( $\max 60 \mathrm{mg}$ ) was given daily until day 30 when it was tapered over a two week course; Cytosine arabinoside (AraC), $70 \mathrm{mg}$ intrathecally (IT); Methotrexate (MTX), $12 \mathrm{mg} \mathrm{IT.}$

\section{ĊASE REPORTs}

\section{Patient 1}

A $83 / 12$ year-old boy developed fatigue, pain in both arms and legs and daily dull headaches two and one-half weeks prior to admission. The total white blood cell count was $55,000 / \mathrm{mm}^{3}$ with $70 \%$ blasts. Bone marrow aspiration showed that the normal hematopoietic cellular elements were almost totally replaced by leukemic blast cells. Lumbar puncture was negative for the presence of malignant cells and cerebrospinal fluid (CSF) protein was $0.32 \mathrm{~g} / \mathrm{L}$. The diagnosis of acute lymphoblastic leukemia of $\mathrm{L}_{2}$ morphology was made and induction therapy was initiated (Figure 1). On day 14 of therapy, CSF protein was $0.2 \mathrm{~g} / \mathrm{L}$ : On day 22 of therapy, he was noted to have a BP of $160 / 110$, but was asymptomatic. The next day he suddenly became unresponsive to commands and required temporary respiratory assistance. Two hours earlier he had been alert and oriented. Pupils were equally dilated to $5 \mathrm{~mm}$, but unreactive to light. The eyes were tonically deviated to the right and the right arm exhibited tonic-clonic movements. There were no signs of meningeal irritation; deep tendon reflexes and plantar reflexes were normal. After intubation, the patient was transferred to the intensive care unit (ICU). A CT scan was obtained and showed mild diffuse enlargement of the ventricular and subarachnoid CSF spaces. Multifocal abnormalities were noted at gray-white junctions and in the cerebral cortex bilaterally: These lesions were associated with diffuse gyriform enhancement compatible with small areas of infarction (Figures $1 \mathrm{~A}$ and $\mathrm{B}$ ). Repeat CT scans showed resolution of the enhancing lesions. EEGs showed generalized excess of slow activity and sharp wave discharges in boith hemispheres. CSF was normal with the exception of a protein level of $0.46 \mathrm{~g} / \mathrm{L}$. Magnetic Resonance Imaging (MRI) with T-2-weighting done 15 months from the onset of encephalopathy showed a few areas of increased signal intensity in the left frontal white matter (Figure $1 \mathrm{C}$ ). Auditory brainstem evoked potentials and somatosensory evóked potentials were normal. Visual evoked potentials showed mild delays and poor reproductibility of P100 waves bilaterally. Two years from the time of acute lymphoblastic leukemia diagnosis, he has severe and widespread neuropsychological deficits (Table 2) and poorly controlled partial complex seizures.

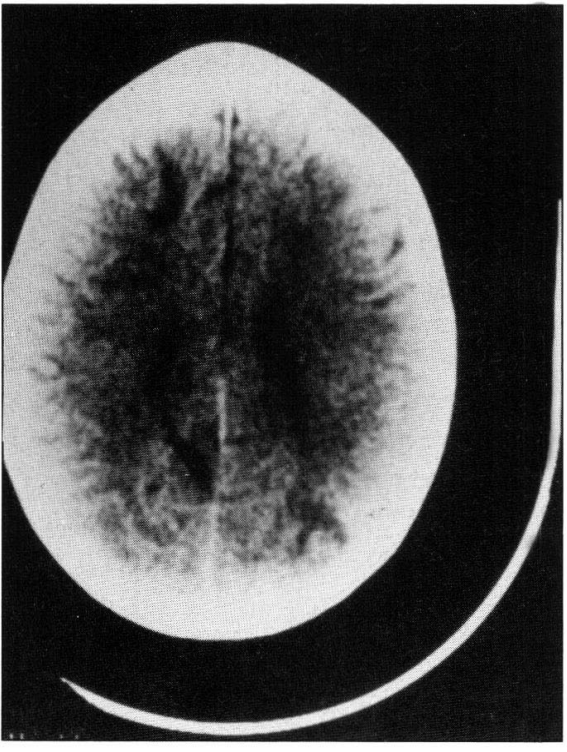

A

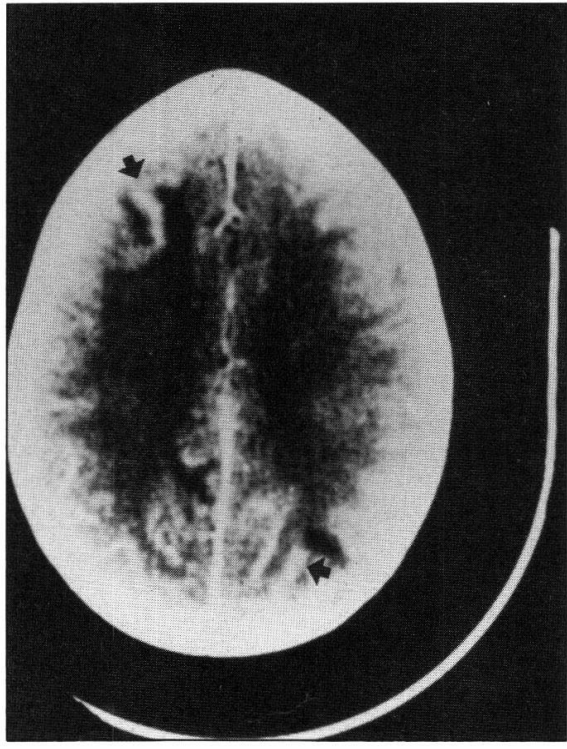

B

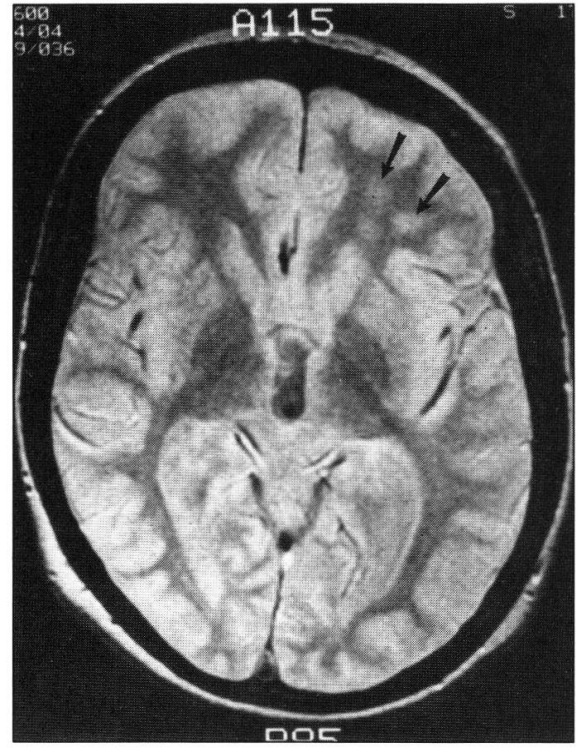

C

Figures I $A, B$, and $C-$ Patient I. Axial $C T$ scans without $(A)$ and with $(B)$ intravenous contrast demonstrate multifocal enhancing lesions at graywhite junctions (arrows). MRI examination with T-2-weighing at time of cognitive testing $(C)$ demonstrates mild cortical atrophy and a few areas of increased signal intensity (arrows) in left frontal white matter. 


\begin{tabular}{|c|c|c|c|}
\hline \multicolumn{4}{|l|}{ Age } \\
\hline Cognitive Testing & $98 / 12$ & $65 / 12$ & $106 / 12$ \\
\hline \multicolumn{4}{|l|}{ Intellectual Function } \\
\hline Overall IQ & $2 \%$ ile & $2 \%$ ile & | \%ile \\
\hline \multicolumn{4}{|l|}{ IQ Subtest Analysis } \\
\hline Knowledge & Low & Very Low & Very Low \\
\hline Verbal Reasoning & Very Low & Below Average & Below Average \\
\hline Mental Computations & Below Average & Low & Very Low \\
\hline Word Knowledge and Usage & Low & Below Average & Below Average \\
\hline Social Judgment & Below Average & Below Average & Below Average \\
\hline Transcription of Symbols & Low & Very Low & Very Low \\
\hline Route Finding (Mazes) & Average & Above Average & Very Low \\
\hline \multicolumn{4}{|l|}{ Language Function } \\
\hline Visual Naming of Objects & Impaired & lmpaired & N/A \\
\hline Sentence Repetition & Impaired & Impaired & $\mathrm{N} / \mathrm{A}$ \\
\hline Word Fluency & Impaired & Impaired & N/A \\
\hline Sentence Construction & Impaired & Impaired & N/A \\
\hline Sentence Comprehension & Impaired & Intact & N/A \\
\hline Articulation of Speech Sounds & Impaired & Intact & $\mathrm{N} / \mathrm{A}$ \\
\hline \multicolumn{4}{|l|}{ Memory } \\
\hline Full Scale Memory Quotient & $\mathrm{N} / \mathrm{A}$ & I \%ile & N/A \\
\hline Recognition of Sequence & $4 \%$ ile & $3 \%$ ile & $\mathrm{N} / \mathrm{A}$ \\
\hline \multicolumn{4}{|l|}{ Long-term Memory } \\
\hline Storage of Words & Impaired & Imparied & N/A \\
\hline List Storage of Words & Impaired & Impaired & N/A \\
\hline Long-Term Story Recall & N/A & Impaired & $\mathrm{N} / \mathrm{A}$ \\
\hline Procedural Learning & UTP & Slow & $\mathrm{N} / \mathrm{A}$ \\
\hline Procedural Memory & UTP & Fair & N/A \\
\hline \multicolumn{4}{|l|}{ Attention } \\
\hline Vigilance & Intact & Impaired & N/A \\
\hline Anticipatory Set & Intact & Impaired & N/A \\
\hline Interference Control & Impaired & Impaired & $\mathrm{N} / \mathrm{A}$ \\
\hline Attention (Ambient Noise) & $1 \%$ ile & $9 \%$ ile & $\mathrm{N} / \mathrm{A}$ \\
\hline Attention (Cafeteria Noise) & i \%ile & $9 \%$ ile & $\mathrm{N} / \mathrm{A}$ \\
\hline Attention (Competing Voice) & $1 \%$ ile & $2 \%$ ile & $\mathrm{N} / \mathrm{A}$ \\
\hline Selective Attention (Overall) & $1 \%$ ile & $1 \%$ ile & $\mathrm{N} / \mathrm{A}$ \\
\hline \multicolumn{4}{|l|}{ Executive Control } \\
\hline Shifting Sets to Form Concepts & Impaired & Impaired & $\mathrm{N} / \mathrm{A}$ \\
\hline Perseveration & Yes & Yes & $\mathrm{N} / \mathrm{A}$ \\
\hline
\end{tabular}

Note: \%ile = percentile rank for age. N/A = test not administered. UTP = Patient unable to perform task. References to the neuropsychological tests used are as follows: Intellectual function, ${ }^{18}$ language, ${ }^{19,20}$ memory quotient, ${ }^{21}$ working and short-term memory, ${ }^{22-24}$ long-term memory, ${ }^{25,26}$ procedural learning and memory, ${ }^{27}$ attention, ${ }^{28}$ and executive control. ${ }^{29.30}$ 


\section{Patient 2}

A $103 / 12$ year-old boy developed fatigue, episodic epistaxis, headaches and poor appetite one month prior to admission. The leukocyte count was $57,500 / \mathrm{mm}^{3}$ with $86 \%$ blasts. Bone marrow aspirate confirmed the diagnosis of acute lymphoblastic leukemia with $\mathrm{L}_{\text {, mor- }}$ phology. CSF was negative for malignant cells and protein was 0.12 $\mathrm{g} / \mathrm{L}$. Induction therapy was initiated (Table 1). On day 30 of therapy, he became unresponsive to verbal commands, and was noted by his parents to be staring into space and jerking both arms and legs. The generalized clonic seizures were treated with diazepam and the hypertension $(190 / 120)$ was treated with hydralazine, nitride and propranolol. He was then transferred to the ICU. On admission, his BP was 140/100 and he was unconscious and flaccid. Nuchal rigidity was present and plantar reflexes were equivocal. Deep tendon reflexes were absent. CT scan (Figures $2 \mathrm{~A}$ and $\mathrm{B}$ ) showed a right parietal rounded area measuring about $3 \mathrm{~cm}$ in diameter with an edematous rim most consistent with a local hemorrhage or hemorrhagic infarction. Serial CT scans demonstrated resolution of the hematoma and persistent cortical atrophy. EEGs showed a generalized excess of slow activity with sharp wave discharges arising from the right hemisphere. CSF protein was $0.3 \mathrm{~g} / \mathrm{L}$ and later decreased to $0.17 \mathrm{~g} / \mathrm{L}$ in follow-up. He became progressively more alert and after discharge received 1800 cGy of prophylactic cranial irradiation. MRI performed 7 years later (Figure $2 \mathrm{C}$ ) showed cerebral and cerebellar atrophy and minimal white matter changes with increased signal intensity on T-2-weighted sequences namely in the parietal regions, but also in the frontal regions.

Seven years from the time of acute lymphoblastic leukemia diagnosis and three years from the discontinuation of chemotherapy, he has remained in remission but has severe and widespread deficits in neuropsychological function (Table 2). Bihemispheric partial complex seizures are frequent and poorly controlled with antiepileptic drugs.

\section{Patient 3}

A $45 / 12$ year-old boy became lethargic, pale and anorectic one week prior to admission. He was irritable, and complained of a stiff neck, joint pains and headaches several days prior to admission. A complete blood count showed anemia, and a leukocyte count of $25,480 / \mathrm{mm}^{3}$ with $19 \%$ blasts. Bone marrow aspiration confirmed the diagnosis of acute lymphoblastic leukemia of $L_{2}$ morphology and lumbar puncture was negative for the presence of leukemic cells. CSF protein was 0.15 $\mathrm{g} / \mathrm{L}$. On day 32 of induction therapy (Table 1), he became obtundant at home and had generalized clonic seizures with episodic deviation of the eyes. The seizures were treated with diazepam and phenobarbital in a local hospital and he was transferred to the ICU.

He was unresponsive to verbal commands, flaccid in all extremities and had tonic deviation of the head to the right. A Brudzinski sign and bilateral Babinski signs were present. CT scan disclosed mild generalized brain atrophy (Figure $3 \mathrm{~A}$ ). MRI (Figure $3 \mathrm{~B}$ ) showed symmetric white matter changes with high signal intensity of T-2-weighted sequences adjacent to the frontal horns and prominently in the parietooccipital regions. EEGs showed generalized excess of slow activity and sporadic sharp wave discharges in both hemispheres. CSF protein at the time of encephalopathy was $0.6 \mathrm{~g} / \mathrm{L}$ and later normalized to $0.18 \mathrm{~g} / \mathrm{L}$. Visual evoked potentials showed slight delays in the P100 waves bilaterally and somatosensory evoked potentials showed a poor response on the left following stimulation of the median nerve; auditory brainstem evoked potentials were normal. He had gradual improvement in his level of consciousness, but vision and general motor function remained poor at the time of discharge from the hospital three months following onset of encephalopathy.

In follow-up, vision and visual evoked potentials normalized, but somatosensory evoked potentials showed persistent abnormalities with delayed and dispersed responses to left median nerve stimulation. He was walking again on his own two months from the time of discharge. He was placed on a modified high risk treatment protocol in which intrathecal methotrexate was eliminated and his leukemia has remained in remission. He has had frequent partial complex seizures that are poorly controlled with antiepileptic drugs. Follow-up CT scan 2 years from the time of encephalopathy (Figure $3 \mathrm{C}$ ) showed cortical atrophy. At age 6 years, 5 months, he has impulsive and aggressive behavior and is performing well below age expectations in those neuropsychological functions that could be tested. (Table 2).

\section{Discussion}

The improvement in survival rates in children with cancer over the last four decades has resulted from strong efforts in clinical research to identify those children with acute lymphoblastic leukemia at risk for relapse and to safely deliver to them intensive therapeutic regimens. Central nervous system

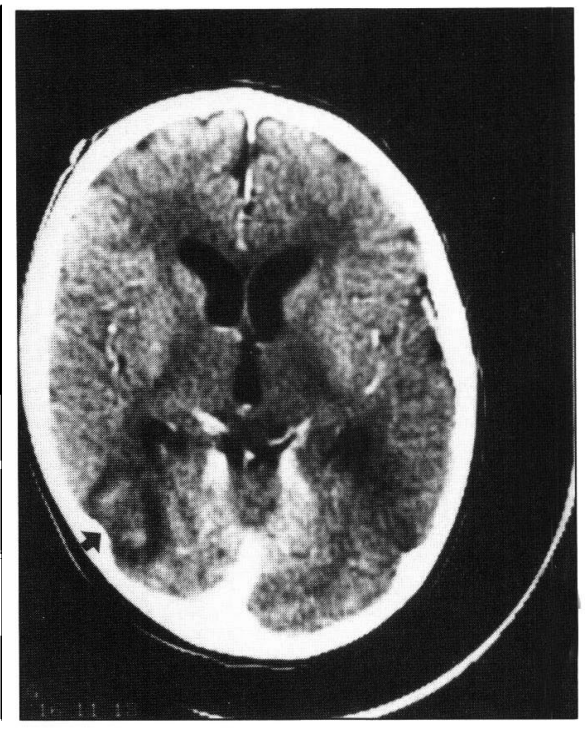

A

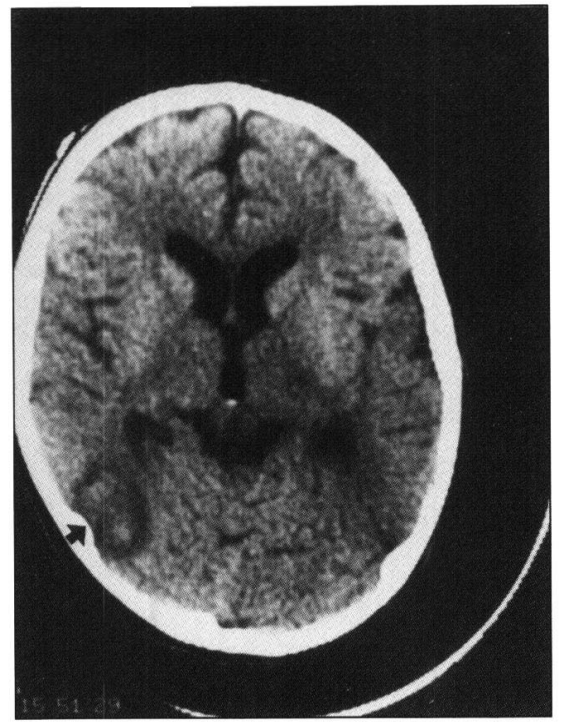

B

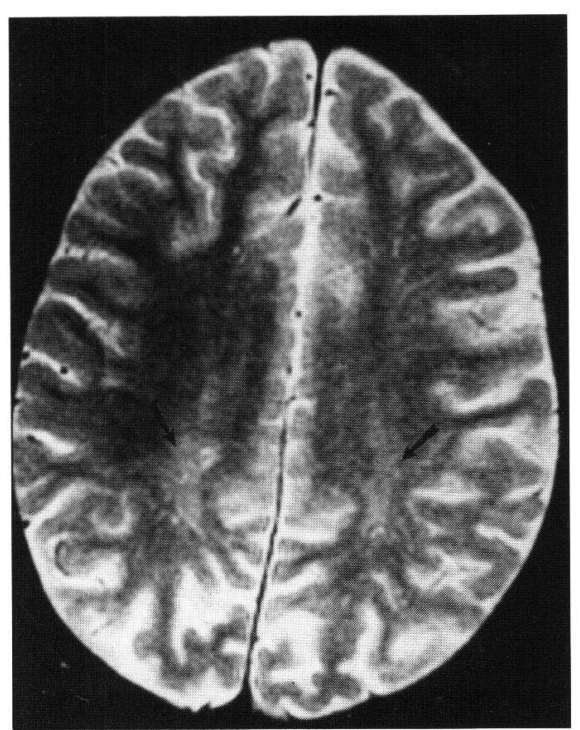

C

Figures 2 A, B and C-Patient 2. CT Scans without (A) and with (B) intravenous contrast demonstrate the presence of a right parietal hematoma with surrounding edema (arrow). MRI examination (C) shows a few areas of increased signal intensity on T-2-weighted sequences in the parietal white matter (arrows) at the time of cognitive testing. 


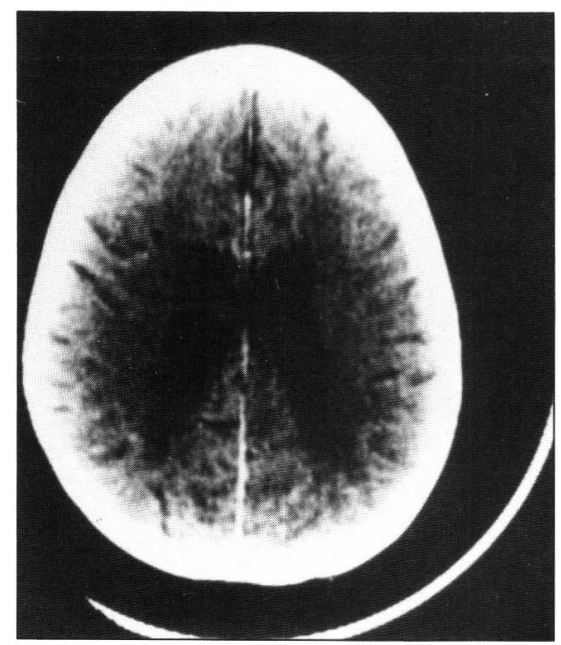

A

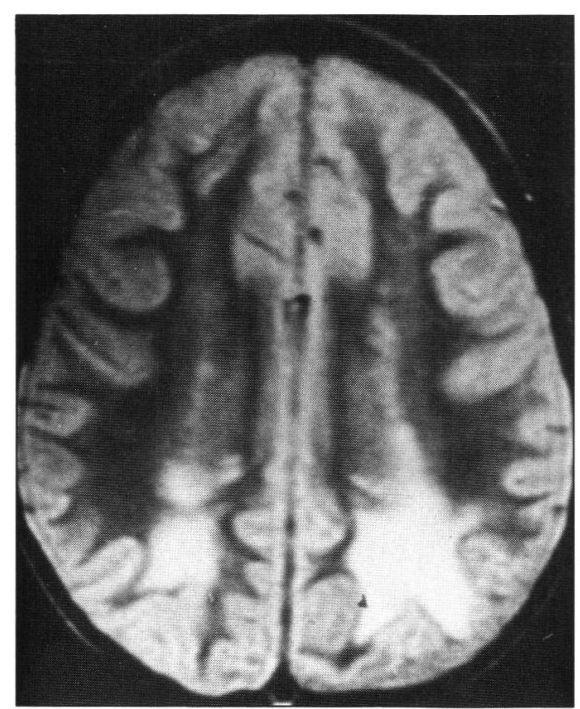

B
Figures $3 A, B$ and $C-$ Patient 3. Axial $C T$ scan $(A)$ discloses mild generalized brain atrophy. MRI with T-2-weighing $(B)$ at the time of acute encephalopathy demonstrates prominent areas of increased signal in the white matter. Follow-up CT scan (C) show's diffuse cortical atrophy at the time of cognirive testing.

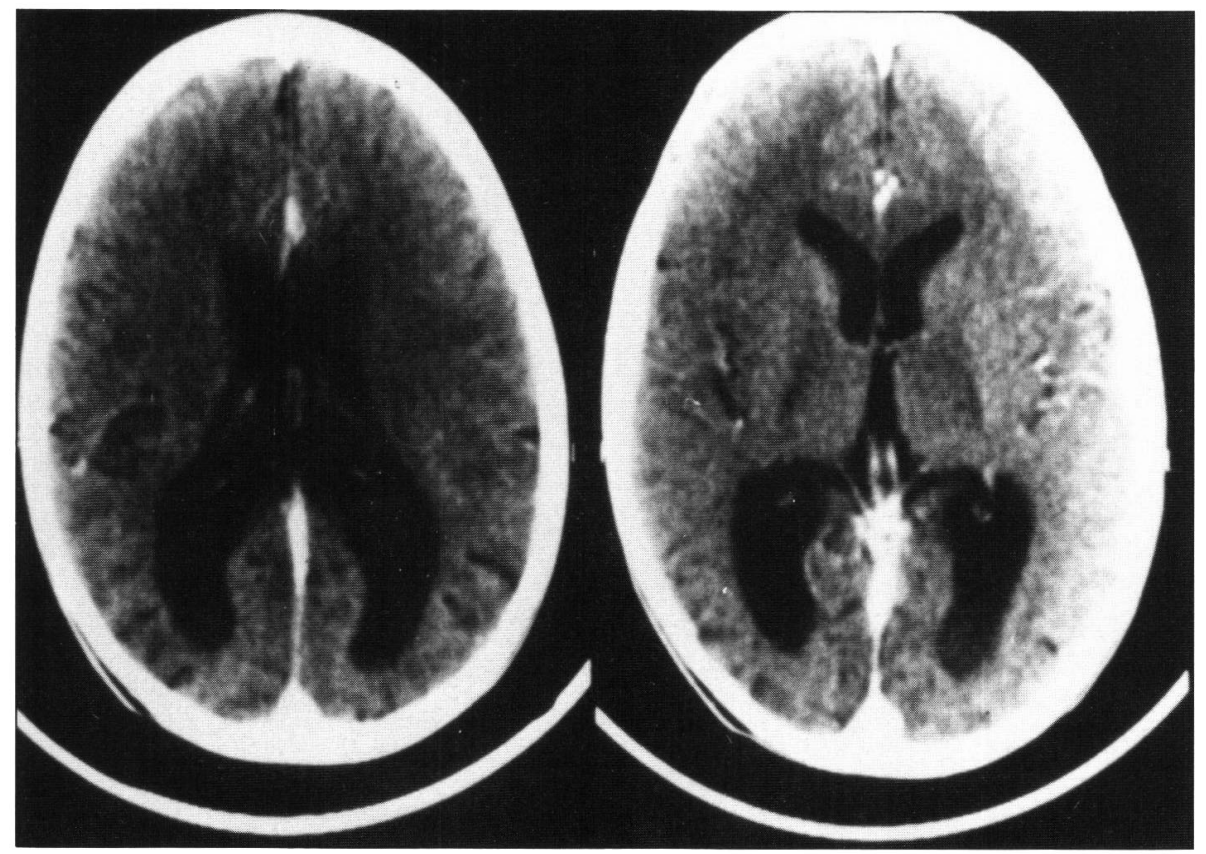

C

prophylaxis with cranial irradiation and chemotherapy has contributed significantly to reducing the occurrence of meningeal leukemia in children with occult disease. However, central nervous system therapy for occult or overt meningeal leukemia has produced a myriad of acute, transient, subacute and chronic neurologic disturbances. The great majority of reports of neurotoxicity from central nervous system therapy have been in children who have received cranial irradiation and chemotherapy. Severe irreversible encephalopathies have developed in children who received 2400 cGy cranial irradiation followed by intravenous methotrexate at a dose of $\geq 40 \mathrm{mg} / \mathrm{m}^{2}$ weekly and many clinicians now avoid this sequence of therapy. ${ }^{7}$ Most of the data on chronic irreversible forms of neurotoxicity pertain to children who have received $2400 \mathrm{cGy}$ cranial irradiation plus intrathecal methotrexate. ${ }^{8,9}$
None of the children in this report had received cranial irradiation prior to the onset of acute encephalopathy. Within the past decade, there has been a trend towards more aggressive chemotherapy regimens in the induction phase of childhood acute lymphoblastic leukemia treatment and cranial irradiation has been withheld. In studies in which prophylactic therapy for central nervous system leukemia was limited to intrathecal methotrexate or cytosine arabinoside and hydrocortisone, no chronic severe neurotoxicity has been reported. The principal forms of toxicity have been arachnoiditis and seizures. Therefore, we report three cases of children who have experienced severe, persistent, medically intractible seizures and broad-based neuropsychological impairment which is probably attributable to the chemotherapy administered during induction. One child (Patient 2) later received prophylactic cranial irradiation 
which may have also contributed to the chronic encephalopathy. However, the close timing of onset of the acute encephalopathy in all 3 patients (Figure 1), the similar clinical course, and the degree of cognitive impairment suggests to us that the induction regimen produced the structural central nervous system abnor: malities and neurologic sequelae. Each patient had received a single dose of intrathecal cytosine arabinoside and only one ( 2 of 3) or two ( 1 of 3 ) doses of intrathecal methotrexate; each child had received multiple doses of vincristine, daunomycin, Lasparaginase and prednisone. L-asparaginase may have accounted for the high density lesion on the CT scan in Patient 2 and the multifocal enhancing lesions in Patient 1. Thrombotic stroke is associated with L-asparaginase therapy but it is unknown what the long-term effects of the drug might be since systematic neuropsychological evaluations have not been reported. ${ }^{10,11}$ It is interesting to note that Ochs reported worsening of neurological findings in a child with L-asparaginase-induced stroke when methotrexate was infused on two separate occasions. ${ }^{6}$ Initial CT scans in L-asparaginase-induced thrombotic stroke may be normal, so it is possible that the drug also contributed to the acute encephalopathy in Patient 3 and the chronic encephalopathy in all three patients. Moreover, L-asparaginase may have placed all three children at risk for neurologic sequelae from the effects of intrathecal/intravenous methotrexate administered during the phases of induction, intensification, maintenance and re-induction.

Conceivably, intrathecal methotrexate may have contributed to the acute encephalopathy. There were no signs of acute chemical meningitis, the most common neurotoxicity from intrathecal methotrexate. Previous studies have shown an absence of white matter changes on neuroimaging in asymptomatic children with acute lymphoblastic leukemia treated with cranial irradiation and intrathecal methotrexate. ${ }^{12.13}$ Unlike other children who have received methotrexate, our patients had MRI findings of white matter disease. In Patient 3 the white matter changes observed at the time of the acute encephalopathy were not consistent with focal cortical injury (e.g., stroke) which might have resulted from L-asparaginase. Moreover, a follow-up CT scan in Patient 3 showed diffuse central nervous system atrophy and not focal encephalomalacia which may be seen from L-asparaginase thrombotic stroke. While cytosine arabinoside may produce neurotoxicity which is similar to that of methotrexate and should therefore be considered as a possible etiological factor, we speculate that the white matter changes on the MRI in all three patients are attributable to methotrexate for the following reasons: 1) intrathecal cytosine arabinoside had been administered more than three weeks earlier in acute lymphoblastic leukemia patients whereas the acute encephalopathy occurred from 5 to 8 days from intrathecal methotrexate administration, and 2) as in our Patient 3, Ebner ${ }^{14}$ reported MRI findings of diffuse hyperintensity of cerebral white matter on T-2-weighted sequences in children with symptomatic methotrexate-induced neurotoxicity. In addition, the neuropsychological testing performed on our patients is consistent with previous reports of methotrexateinduced encephalopathy. ${ }^{15-17}$ Since cerebrospinal fluid levels of methotrexate were not measured, it is not known if the neurotoxicity which occurred is related to differences in the rate of metabolism of methotrexate.

Risk factors for the development of $\mathrm{L}$-asparaginase or methotrexate neurotoxicity are unknown. Conceivably, Lasparaginase may have increased the risk of methotrexate neuro- toxicity in all three patients. The treatment correlates of impaired neuropsychological function, as well as the consistency of neuropsychological deficits in patients having similar treatment regimes, remain to be studied in national cancer groups.

\section{REFERENCES}

1. Aur RJ, Hustu HO, Verzosa MS, et al. Comparison of two methods of preventing central nervous system leukemia. Blood 1973; 42: 349-357.

2. George SL, Ochs J, Mauer AM, et al. Importance of isolated CNS relapse in children with acute lymphoblastic leukemia. J Clin Oncol 1985; 3: 776-781.

3. Ortega JA, Nesbit ME, Sather HN, et al. Long-term evaluation of CNS prophylaxis trial - treatment comparison and outcome after CNS relapse in ALL: a report from the Children's Cancer Study Group. J Clin Oncol 1987; 5: 1646-1654.

4. Duffner PK, Cohen, ME. Long-term consequences of CNS treatment for childhood cancer, Part I: pathologic consequences and potential for oncogenesis. Pediatr Neurol 1991; 7: 157-163.

5. DiMario FJ Jr, Packer RJ. Acute mental status changes in children with systemic cancer. Pediatrics 1990; 85: 353-360.

6. Ochs J. Neurotoxicity due to central nervous system therapy for childhood leukemia. Am J Pediatr Hematol Oncol 1989; 11: $93-$ 105.

7. Bleyer WA, Popleck DG. Prophylaxis and treatment of leukemia in the central nervous system and other santuaries. Semin in Oncol 1985; 12: 131-148.

8. Ocho JJ, Parvey LS, Whitaker JN, Bowman WP, et al. Serial cranial computed-tomography scans in children with leukemia given two different forms of central nervous system therapy. $J$ Clin Oncol 1983; 1: 793-798.

9. Duffner PK, Cohen, ME. Long-term consequences of CNS treatment for childhood cancer, Part II: clinical consequences. Pediatr Neurol 1991; 7: 237-242.

10. Pui CH, Chesney CM, Weed J, Jackson CW. Altered von Willebrand factor molecule in children with thrombosis follow: ing asparaginase-prednisone-vincristine therapy for leukemia. $J$ Clin Oncol 1985; 3: 1266-1272.

11. Packer RJ, Rorke LB, Lange BJ, Seigel KB, Evans AE. Cerebrovascular accidents in children with cancer. Pediatrics 1985; 76: 194-201.

12. Hara T, Kishikawa T, Miyazaki S, Ishii E, Goya N. Central nervous system complications in childhood leukemia. Correlation between clinical and computed tomographic finding. Am J Pediatr Hematol Oncol 1984; 6: 129-136.

13. Kramer JH, Norman D, Brant-Zawadzki M, Ablin A, Moore IM. Absence of white matter changes on magnetic resonance imaging in children treated with CNS prophylaxis therapy for leukemia. Cancer 1988; 61: 928-930.

14. Ebner F, Ranner G, Slave I, et al. MR findings in methotrexateinduced CNS abnormalities. Am J Neuroradiol 1989; 10: 959964.

15. Fairclough D, Ochs J, Mulhern R, et al. Comparison of neuropsychologic functioning and clinical indicators of neurotoxicity in long-term survivors of childhood leukemia given cranial radiation or parenteral methotrexate: a prospective study. J Clin Oncol 1991; 9: 145-151.

16. Lazarus K, Cairo MS, Gilmore RL, et al. Intracranial hemorrhage and focal seizures secondary to use of L-asparaginase during induction therapy of acute lymphocytic leukemia. J Pediatr 1980; 97: 829-833.

17. Rivera GK, Kovnar E, Pui $\mathrm{CH}$, et al. Limiting toxicities during intensified remission induction chemotherapy for childhood acute lymphocytic leukemia. Hamatol-Bluttransfus 1987; 30: 156-160.

18. Wechsler D, Wechsler Intelligence Scale for Children - Revised. NY: The Psychological Corporation, 1974.

19. Spreeno O and Benton AI. Neurosensory center comprehensive examination for aphasia: Manual of Directions. Victoria, BC: Neuropsychology laboratory, U. Victoria, 1969. 
20. Gaddes WH and Crockett DJ. The spreen-Benton aphasia tests, normative data as a measure of normal language development. Brain Lang 1975: 2: 257-280.

21. Larrabee GJ, Curtiss G. Factor structure and construct validity of the Denman Neuropsychology Memory Scale. Int J Neurosci 1985; 26: 269-276.

22. Ryan EB, Siegel LS. The development of working memory in normally achieving and subtypes of learning disabled children. Child Dev 1989; 60: 973-980.

23. Webster RE. Learning Efficiency Test. Novato, CA: Academic Therapy Publications, 1981.

24. Fristoe M, Goldman R. Assessment of various auditory perceptual and cognitive skills. J Commun Disord 1975; 8: 171-180.

25. Fletcher JM. Memory for verbal and nonverbal stimuli in learning disability subgroups: analysis by selective reminding. J Exp Child Psychol 1985; 40: 244-259.
26. Johnson NS, Mandler JM. Some of the thousand words a picture is worth. J Exp Psychol Hum Learn 1976; 2: 529-540.

27. Saint-Cyr JA, Taylor AE, and Lang AE. Procedural learning and neostriatal dysfunction in man. Brain 1988; 111: 941-959.

28. Gordon $M$. Errors of omission and commission: a response to Milich and colleagues regarding the Gordon Diagnostic System. Psychopharmacol Bull 1987; 23: 325-328.

29. Heaton RK, Pendleton MG. A comparison of the Wisconsin card sorting test and the category test. J Clin Psychol 1982; 38: 392396.

30. Chelune GJ, and Baer RA. Developmental norms for the Wisconsin card sorting test. J Clin Exp Neuropsychol 1986; 8: 219-228. 